Jurnal Agro 7(1), 2020

\title{
KONSERVASI IN VITRO DUA AKSESI LILI MELALUI MODIFIKASI MEDIA KULTUR
}

\section{IN VITRO CONSERVATION OF TWO LILIUM ACCESSIONS THROUGH CULTURE MEDIUM MODIFICATION}

\author{
Kurniawan Budiarto ${ }^{*}$, Indijarto Budi Rahardjo², Hanudin² dan Wakiah Nuryani ${ }^{2}$ \\ ${ }^{1)}$ Balai Penelitian Tanaman Jeruk dan Buah Subtropika, Jl. Raya Tlekung No.1Junrejo, Kota Batu \\ (65327), Jawa Timur \\ ${ }^{2)}$ Balai Penelitian Tanaman Hias, Jl. Raya Pacet - Ciherang, Ciherang, Pacet, Cianjur (43253), Jawa \\ Barat \\ Korespondensi :kbud1arto@gmail.com
}

Diterima: 12 Februari 2019/Disetujui : 29 oktober 2019

\begin{abstract}
ABSTRAK
Konservasi in vitro merupakan salah satu al ternatif penyimpanan materi genetik dalam kondisi aseptik. Metode ini dapat mengurangi resiko kepunahan materi genetik akibat kondisi lingkungan yang ekstrem dan kerumitan pengelolaan pada skala in vivo terutama untuk tanaman yang berasal dari subtropis, seperti lili. Metode penghambatan pertumbuhan dan ketahanan plantlet selama perlakuan konservasi merupakan faktor penting untuk kelangsungan hidup materi genetik yang disimpan. Penelitian bertujuan untuk mengevaluasi media konservasi melalui modifikasi kandungan nutrien dan konsentrasi sukrosa untuk konservasi in vitro jangka menengah te rhadap dua aksesi lili yaitu lokal Lilium longiflorum dan cv. Candilongi. Penelitian dilakukan di Balai Penelitian Tanaman Hias mulai Januari 2015 sampai September 2017. Hasil penelitian menunjukkan laju kematian plantlet semakin meningkat seiring dengan lamanya waktu penyimpanan. Laju kematian plantlet dengan pertumbuhan daun yang terendah diperlihatkan oleh plantlet Lili yang dikonservasi pada media $1 / 4 \mathrm{MS}+7 \%$ sukrosa dengan kisaran $27-31 \%$ setelah 24 bulan penyimpanan. Dua genotipe lili menunjukkan respon pertumbuhan yang berbeda selama konservasi in vitro dan in vivo, namun tidak pada media konservasi yang dicoba. Plantlet lili lokal $L$. longiflorum mempunyai jumlah daun lebih sedikit selama konservasi in vitro. Sedangkan cv. Candilongi memperlihatkan tinggi tanaman yang lebih rendah dengan jumlah bunga lebih banyak dan ukuran bunga lebih besar pada evaluasi in vivo.
\end{abstract}

Kata kunci: keragaan in vivo, konsentrasi sukrosa, konservasi in vitro, Lili, modifikasi media

\section{ABSTRACT}

In vitro conservation is an alternative method of plant genetic resources prese rvation in aseptic condition. The method has successfully applied in many crops and reduced the limitation of in vivo conservation of non-native crop as Lily planted in the tropic area. Growth inhibition method and plantlet resistance are important factors to ensure the life-span of the conserved

Cyte this as: Budiarto, K., Rahardjo, I, B., Hanudin, \& Nuryani, W. (2020). Konservasi in vitro dua aksesi lili mealui modifikasi media kultur. JurnalAgro, 7(1), 1-13. https://doi.org/10.15575/4179 
plantlet during in vitro storage. The research aimed to evaluate the media compositions and sucrose concentrations for mid-term conservation of two Lilium accessions, local L. longiflorum and cv. Candilongi. The experiment was carried out at Indonesian Ornamental Crops Research Institute from January 2015 to September 2017. The results showed the plantlet death rates increased in line with the duration of storages. After 24 months storage, plantlets conserved under $1 / 4 \mathrm{MS}+7 \%$ sucrose showed fewer numbers of leaves and death plantlets in the ran ge of $27-31 \%$. Growth plantlet retardation during storage was merely detected on local L. longiflorum that showed less leaves development. Plantlet of cv. Candilongi had shorter plant height, yet bigger flower size and higher number of flower per plant under in vivo evaluation.

Keywords: in vitro conservation, in vivo performances, Lilium, media modification, sucrose concentrations

\section{PENDAHULUAN}

Lili (Lilium sp) merupakan salah satu tanaman hias bunga potong yang banyak diperdagangkan di dunia. Genus Lilium mempunyai lebih dari 100 spesies yang tersebar dari Sierra Nevada dan pegunungan Rocky hingga sebelah timur Amerika Utara melalui Eropa, Timur Tengah hingga Pengunungan Caucasus, Siberia dan sebelah timur Asia (Balangcod et al., 2011; Gao et al., 2015; ikinci et al., 2006). Sentra produksi lilidi Indonesia umumnya berada di dataran tinggi di daerah Cianjur, Bandung, Sukabumi, Malang, dan Bali (Pramanik \& Rachmawati, 2010). Pengembangan agribisnis tanaman Iili juga didukung dengan hadirnya varietas unggul baru nasional hasil rakitan dalam negeri yang adaptif di kondisi tropis seperti Indonesia (Sanjaya, 2010).

Tanaman lili mempunyai siklus hidup lebih dari satu musim (biannual) di daerah aslinya. Spesies lili dapat membentuk biji secara alami dan berkecambah membentuk umbi mikro. Dalam pertumbuhannya, umbi mini ini berkembang membesar dengan membentuk daun-daun roset (sisik umbi) pada musim panas dan menggugurkan daunnya pada musim gugur (Mojtahedi et al., 2013). Dalam proses pembesaran, umbi utama juga membentuk umbi-umbi mini baru. Umbi dengan daun yang gugur akan tetap dorman selama musim dingin (Asker, 2012). Umbi akan membentuk batang utama yang tumbuh memanjang pada suhu lingkungan yang mulai menghangat pada musim semi dan berbunga pada ujung terminal (Lucidos et al., 2013). Proses pembesaran umbi yang lama dan kebutuhan suhu dingin dalam siklus fisiologisnya menyulitkan pelestarian dan pengelolaan plasma nutfah secara in vivo di daerah tropis seperti di Indonesia. Konservasi in vivo membutuhkan tempat yang luas dengan kondisi lingkungan yang terkendali sesuai dengan sifat tanaman yang umumnya berasal dari daerah subtropis (Engelmann, 1991). Pada konservasi in vivo juga beresiko terjadinya kesalahan pelabelan akibat kesalahan manusia dan terjadinya kehilangan atau kematian materi genetik akibat serangan hama dan penyakit serta bencana alam (Kaviani, 2011).

Konservasi in vitro merupakan alternatif metode konservasi yang dapat meminimalisir kendala konservasi in vivo. Pada konservasi in vitro, materi genetik ditanam di dalam botol 
dan disimpan dalam tempat yang terkontrol sehingga hanya memerlukan ruangan yang lebih sempit untuk menyimpan materi genetik dalam jumlah yang besar. Konservasi in vitro juga mengurangi kehilangan atau matinya materi genetik akibat serangan hama dan penyakit karena ditanam pada media aseptik dalam botol (Rao, 2004).

Pada konservasi in vitro, materi genetik yang ditanam dalam media aseptik dan diinduksi dalam pertumbuhan minimal melalui perlambatan proses pembelahan sel tetapi tidak mematikan jaringan. Induksi perlambatan pertumbuhan umumnya menggunakan satu atau kombinasi metodemetode sebagai berikut: pengurangan hara (Bonnier, 1997), peningkatan sukrosa dan penggunaan zat penghambat tumbuh seperti ABA (Yung-Peng et al., 2012), pengurangan komposisi garam makro dan mikro menjadi $1 / 2$ sampai $1 / 4$ komposisi normal (Yung-Peng et al., 2012), penurunan suhu sampai $4-12^{\circ} \mathrm{C}$ (Devi, Sahoo et al., 2015; Ozen et al., 2016), memberikan tekanan osmotik dengan menambahkan bahan osmotik seperti manitol atau sukrosa dan penggunaan zat penghambat pertumbuhan seperti asam absisat/ABA (Cha-um \& Kirdmanee, 2007), penggunaan retardan seperti paclobutrazol, B-9 dan ancymidol (Dhyani et al., 2014), dan menurunkan tekanan atmosfir atau oksigen (Dhyani et al., 2017). Beberapa penelitian menunjukkan bahwa penggunaan media dengan konsentrasi nutrien tinggi justru berakibat pada peningkatan laju pertumbuhan. Selain itu juga dapat digunakan tempat kultur yang lebih besar dan lebih banyak volume medium untuk menghindarkan plantlet dari kekurangan nutrisi selama penyimpanan (Tahtamouni et al., 2015).

Organ umbi merupakan pusat titik tumbuh tanaman lili sehingga upaya memperlambat pertumbuhan umbi mini (pembentukan sisik umbi dan umbi mini baru) merupakan faktor yang menentukan kehidupan materi genetik selama periode konservasi tertentu. Sisik umbi merupakan tempat penyimpanan makanan (Zhang \& Jia, 2014) sehingga penekanan pertumbuhan umbi mini akan memperlambat perbesaran umbi dan pertumbuhan daun. Perlambatan pertumbuhan umbi mini dapat dilakukan dengan modifikasi media dengan pengurangan konsentrasi nutrien (Syahid \& Bermawie, 2000) dan peningkatan konsentrasi sukrosa (Huh et al., 2016) dengan maksud meningkatkan tekanan osmotik untuk penurunan kelarutan nutrisi pada media. Berdasarkan hal tersebut, penelitian ini bertujuan untuk mengetahui pengaruh media kultur melalui modifikasi komposisi garam makro dan mikro serta konsentrasi sukrosa untuk konservasi aksesi lili secara in vitro.

\section{BAHAN DAN METODE}

Penelitian dilakukan dari bulan Januari 2015 sampai Desember 2017 di Kebun Percobaan Segunung, Balai Penelitian Tanaman Hias (Balithi) yang berlokasi pada ketinggian 1100 mdpl. Penelitian menggunakan rancangan acak kelompok (RAK) pola faktorial dengan lima ulangan. Faktor pertama adalah dua aksesi lili yaitu Lilium longiflorum lokal dan cv. Candilongi. Sedangkan faktor kedua adalah jenis media konservasi yang terdiri dari $1 / 4 \mathrm{MS}+7 \%$ sukrosa, $1 / 4 \mathrm{MS}+9 \%$ sukrosa, $1 / 2 \mathrm{MS}+7 \%$ 
sukrosa, $1 \frac{1}{2} \mathrm{MS}+9 \%$ sukrosa, MS + $7 \%$ sukrosa, dan MS + 9\% sukrosa. Setiap kombinasi perlakuan mempunyai 60 tanaman sampel pada setiap ulangan. Tahapan percobaan ini meliputi persiapan bahan eksplan, penanaman eksplan dan perbanyakan plantlet, inokulasi umbi mini pada media konservasi dan pemeliharan plantlet terkonservasi serta pengujian in vivo plantlet terkonservasi.

\section{Persiapan bahan eksplan}

Bahan eksplan berupa umbi dari masingmasing varietas lili berdiameter $5-7 \mathrm{~cm}$ diperoleh dari Unit Pengelola Benih Sumber (UPBS) Balithi. Umbi-umbi tersebut ditanam pada baki porous dengan media arang sekam dengan ketebalan $5 \mathrm{~cm}$ dan dipelihara di bawah kondisi rumah kaca. Setiap dua hari sekali, umbi-umbi tersebut disiram dengan larutan bakterisida dan fungisida Oksitetrasiklin $150 \mathrm{~g} \mathrm{l}^{-1}$. Setelah 3 minggu, umbi-umbi ini kemudian dibersihkan pada air mengalir dan dibawa ke dalam laboratorium untuk sterilisasi. Umbi direndam pada larutan fungisida Mancozeb $2 \mathrm{~g} \mathrm{l}^{-1}$ selama 30 menit. Setelah ditiriskan, sisik-sisik umbi kemudian dipisahkan dari umbi utama dan dimasukan dalam air steril. Tahapan sterilisasi selanjutnya dilakukan di dalam Laminair Air Flow Cabinet (LAFC).

Sisik-sisik umbihasil pemisahan dari u mbi besar dimasukkan dalam larutan $\mathrm{NaOCl} 2 \%$ dan digoyang perlahan sekitar 1 menit. Sisi umbi kemudian dikeluarkan dan dimasukkan kembali ke dalam larutan yang sama pada konsentrasi $1 \%$ dan digoyang perlahan selama 2 menit. Setelah ditiriskan, umbi direndam dalam larutan alkohol berturut-turut pada konsentrasi $80 \%$ dan $70 \%$ kemudian digoyang perlahan selama 1 menit. Sisik umbi kemudian dibilas dengan aquadest 2 kali dan dikeringkan dengan menempatkannya di atas kertas saring dalam cawan Petridish. Sisik umbi tersebut menjadi bahan eksplan untuk ditanam pada media induksi.

\section{Penanaman eksplan dan perbanyakan plantlet}

Eksplan ditanam pada media $\mathrm{MS}+1 \mathrm{mg} \mathrm{l}^{-1}$ $\mathrm{BA}+1 \mathrm{mg} \mathrm{l}^{-1}$ NAA (El-Naggar et al., 2012) untuk menginduksi pembentukan tunas secara langsung. Tunas yang tumbuh kemudian disubkultur pada media yang sama untuk mendapatkan plantlet yang seragam. Setelah tunas tumbuh dan mempunyai minimal 2 daun (4 - 5 minggu setelah tanam), tunas kemudian disubkultur untuk pembentukan umbi mini (bulbet) pada media MS + $1.5 \mathrm{mg} \mathrm{l}^{-1}$ BAP (Marijana et al., 2012). Subkultur dilakukan beberapa kali hingga jumlah umbi mini mencukupi sebagai materi pengujian konservasi.

\section{Inokulasi umbi mini pada media konservasi} dan pemeliharan plantlet terkonservasi

Media padat perlakuan konservasi ditempatkan pada botol berdiameter $3 \mathrm{~cm}$ dengan tinggi $9 \mathrm{~cm}$ dengan volume $7 \mathrm{ml}$ per botol. Umbi mini diseleksi dan bulbet yang digunakan mempunyai diameter minimal 0.5 $\mathrm{cm}$. Daun bulbet dipotong dan bulbet ditanam pada media konservasi. Bulbet dipelihara pada lemari pendingin dengan suhu $18^{\circ} \mathrm{C}$ dengan penerangan 1000 lux selama 5 hari. Setelah 5 hari, lampu dimatikan dan suhu lemari penyimpanan diturunkan $2^{\circ} \mathrm{C}$ setiap dua hari hingga suhu di dalam lemari penyimpanan mencapai $4^{\circ} \mathrm{C}$. Plantlet 
kemudian disimpan selama 24 bulan (2 tahun).

\section{Pengujian in vivo plantlet terkonservasi}

Setiap 4 bulan sekali sebanyak 10 plantlet pada setiap kombinasi perlakuan dipindahkan ke lemari berpendingin lain. Suhu pada lemari berpendingin ini dinaikkan $2^{\circ} \mathrm{C}$ setiap dua hari hingga mencapai $18^{\circ} \mathrm{C}$. Planlet kemudian dipindahkan pada ruangan inkubasi bersuhu $18-21^{\circ} \mathrm{C}$ dan diberi cahaya dengan intensitas 1000 Iux selama 7 hari. Plantlet bulbet kemudian disubkultur pada media $\mathrm{MS}+2 \mathrm{mg}$

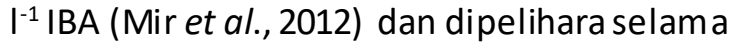
25 hari untuk menginduksi pertumbuhan akar. Plantlet yang telah berakar kemudian diaklimatisasi pada media arang sekam pada baki selama 1 bulan. Tanaman muda hasil aklimatisasi kemudian ditanam pada bedengan dan dipelihara secara standar hingga berbunga.

Pengamatan plantlet meliputi persentase kematian tanaman setiap 4 bulan dan keragaan plantlet yang meliputi jumlah daun dan warna plantlet serta fenomena visual lain pada plantlet. Pada pengujian in vivo, parameter pengamatan yang diamati meliputi tinggi tanaman, jumlah bunga per tanaman, lebar bunga mekar, dan warna bunga. Ratarata hasil pengamatan dianalisis dengan menggunakan ANOVA dan dilanjutkan dengan uji beda nyata terkecil (BNT) pada selang kepercayaan $\geq 95 \%$.

\section{HASIL DAN PEMBAHASAN}

\section{Persentase kematian plantlet}

Hasil analisis sidik ragam menunjukkan bahwa tidak terdapat interaksi antara aksesi lili dan media konservasi. Tingkat kematian plantlet dua asesi lili cenderung meningkat pada setiap durasi pengamatan yang dilakukan setiap 4 bulan dengan trend yang hampir sama (Gambar 1). Persentase kematian plantlet pada 2 aksesi lili yang dicoba hampir sama, yaitu mencapai $46,3 \%$ pada aksesi L. longiflorum lokal dan $47,5 \%$ pada plantlet cv. Candilongi setelah 24 bulan penyimpanan pada suhu dingin (Tabel 1 ). Hal ini mengindikasikan bahwa kedua aksesi lili mempunyai sifat retensi ketahanan yang hampir sama terhadap perlakuan media konservasi. Sifat ketahanan yang hampir sama ini diduga berhubungan dengan latar belakang genetik kedua aksesitersebut. Bonnier \& van Tuyl (1997) juga mendapatkan perbedaan tingkat kematian plantlet pada genotip yang berbeda pada konservasi in vitro lili yang disimpan pada suhu ruangan $\left(25^{\circ} \mathrm{C}\right)$.

Tabel 1. Persentase kematian plantlet pada dua asesilili dan media konservasi in vitro setelah 24 bulan penyimpanan.

\begin{tabular}{lc}
\hline \multicolumn{1}{c}{ Media } & $\begin{array}{c}\text { Persentase kematian } \\
\text { plantlet setelah 24 } \\
\text { bulan penyimpanan (\%) }\end{array}$ \\
\hline Asesi lili & $46,3 \mathrm{a}$ \\
- L. longiflorum & $47,5 \mathrm{a}$ \\
- cv. Candilongi & \\
& \\
Media konservasi & \\
- 1/4 MS + 7\% sukrosa & $29,0 \mathrm{a}$ \\
- 1/4 MS + 9\% sukrosa & $45,5 \mathrm{~b}$ \\
- $1 / 2 \mathrm{MS}+7 \%$ sukrosa & $42,0 \mathrm{~b}$ \\
- $1 / 2 \mathrm{MS}+9 \%$ sukrosa & $53,5 \mathrm{c}$ \\
- MS + 7\% sukrosa & $45,0 \mathrm{~b}$ \\
- MS + 9\% sukrosa & $66,5 \mathrm{~d}$ \\
\hline
\end{tabular}

Keterangan: Angka-angka yang diikuti huruf yang sama pada kolom yang sama tidak berbeda nyata berdasarkan uji Beda Nyata Terkecil ( $\alpha=5 \%$ ). 
(a)

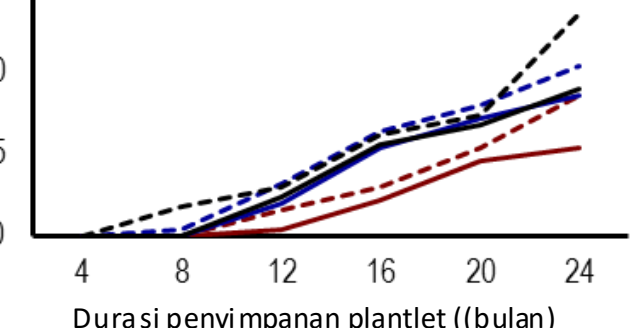

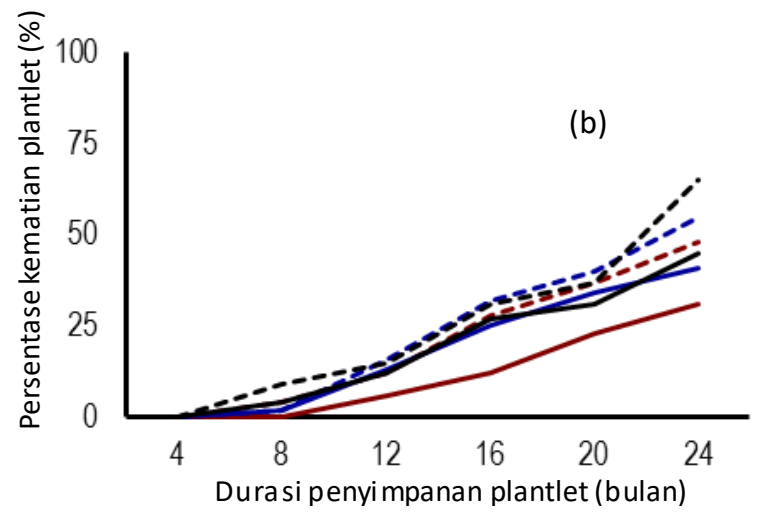

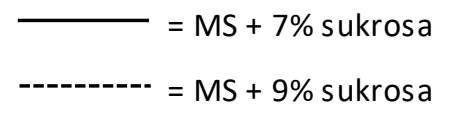

Gambar 1. Persentase kematian plantlet lili terkonservasi (a) L. longiflorum lokal dan (b) cv. Candilongi pada media konservasi yang berbeda.

Secara umum, awal kematian plantlet terdeteksi setelah 8 bulan penyimpanan (Gambar 1). Pada L. longiflorum lokal, kematian awal plantlet terjadi pada media $1 / 2$ MS dan MS yang diberi penambahan sukrosa pada konsentrasi 9\%. Sedangkan pada cv. Candilongi, kematian plantlet awal terjadi pada semua media konservasi kecuali $1 / 4 \mathrm{MS}+$ $7 \%$ sukrosa. Laju kematian plantlet kemudian semakin meningkat sejalan dengan bertambahnya durasi penyimpanan. Pada kedua aksesi lili yang dicoba, kematian plantlet terlihat lebih tinggi pada media konservasi dengan penambahan sukrosa $9 \%$ dengan kisaran 45,5-66,5\% (Tabel 1). Penambahan konsentrasi sukrosa ditujukan untuk menambah tekanan osmotik pada media sehingga ketersediaan nutrisi dan air menjadi menurun bagi plantlet (Keatmetha et al., 2006). Kondisi ini diharapkan dapat menurunkan laju pertumbuhan plantlet (ElBahr et al., 2016). Sedangkan, pada suhu rendah $\left(4^{\circ} \mathrm{C}\right)$, dormasi umbi umumnya patah (Langens-Gerrits et al., 2003) sehingga plantlet mempunyai kecenderungan untuk tumbuh dengan membentuk daun dan organ lainnya. Pembentukan organ-organ seperti daun membutuhkan energi yang pada akhirnya ditranslokasi dari cadangan makanan yang tersimpan dalam sisik umbi (Zhang et al., 2011). Kondisi ini diduga mengakibatkan ketidakseimbangan antara pasokan dan translokasi nutrisi dalam tub uh plantlet sehingga mengakibatkan kematian plantlet lebih tinggi.

Berdasarkan konsentrasi media MS, plantlet yang dikonservasi pada media MS penuh menunjukkan tingkat kematian yang lebih tinggi (45-66,5\%) dibandingkan dengan $1 / 2$ MS (42-53,5\%) dan $1 / 4$ MS (29-45,5\%) (Tabel 1). Tingkat kematian plantlet terkonservasi yang rendah pada $1 / 4 \mathrm{MS}$ diduga berhubungan dengan induksi yang diberikan dengan minimnya nutrisi yang tersedia saat 
awal isolasi. Rendahnya konsentrasi akan menginduksi umbi mini dalam masa dormansi (Mojtahedi et al., 2014). Kondisi ini bersifat kontradiktif dengan suhu rendah yang cenderung membuat patahnya dormasi umbi sehingga diduga proses pemecahan dormansi umbi berjalan lebih lambat. Lambatnya pemecahan dormansi umbi mengakibatkan proses pembentukan organorgan pertumbuhan yang menguras cadangan makanan berjalan lebih lambat dan meningkatkan ketahanan plantlet untuk penyimpanan lebih lama pada suhu rendah.

\section{Keragaan pertumbuhan plantlet terkonservasi}

Jumlah daun dan warna plantlet dua aksesi lili yang dikonservasi pada media yan g berbeda disajikan pada Tabel 2. Hasil analisis sidik ragam menunjukkan bahwa tidak terdapat interaksi yang signifikan antara perlakuan media konservasi dan aksesi lili terhadap jumlah daun plantlet.

Semua plantlet berwarna putih yang diduga diakibatkan kondisi gelap selama proses penyimpanan. Kondisi gelap ini ditujukan untuk mengurangi aktifitas metabolisme sel sehingga proses respirasi plantlet dapat ditekan (Hassan et al., 2014). Menurunnya aktifitas mebolisme sel diharapkan dapat menurunkan laju pertumbuhan plantlet dan translokasi cadangan makanan sehingga plantlet dapat bertahan hidup lebih lama (Shawky \& Aly, 2007).

Jumlah daun plantlet meningkat seiring dengan meningkatnya konsentrasi nutrisi media MS (Tabel 2). Sedangkan pengaruh perbedaan konsentrasi sukrosa pada konsentrasi MS yang sama tidak signifikan terhadap jumlah daun plantlet terkonservasi setelah 24 bulan penyimpanan. Kondisi ini mengindikasikan bahwa rendahnya konsentrasi nutrisi menginduksi penekanan pertumbuhan daun dan sebaliknya makin tinggi konsentrasi nutrisi MS dapat menginduksi pembentukan daun yang lebih tinggi. Keragaan plantlet $L$. longiflorum lokal dan cv. Candilongi yang dikonservasi pada konsentrasi media MS yang berbeda setelah 24 bulan penyimpanan disajikan pada Gambar 2. Fenomena meningkatnya laju pertumbuhan pada konsentrasi nutrisi yang tinggi juga dilaporkan pada konservasi in vitro pisang (Edirisinghe et al., 2017), carica (Rahayu \& Habibah, 2016) dan Smallanthus sonchifolius (Skalova et al., 2012).

Tabel 2. Jumlah daun dan warna plantlet pada dua asesi lili dan media konservasi in vitro setelah 24 bulan penyimpanan.

\begin{tabular}{|c|c|c|}
\hline Perlakuan & $\begin{array}{l}\text { Jumlah } \\
\text { daun*) }\end{array}$ & $\begin{array}{c}\text { Warna } \\
\text { plantlet }\end{array}$ \\
\hline \multicolumn{3}{|l|}{ Aksesilili } \\
\hline - L. longiflorum & $3,5 \mathrm{a}$ & Putih \\
\hline - cv. Candilongi & $4,3 b$ & Putih \\
\hline \multicolumn{3}{|l|}{ Media konservasi } \\
\hline$-1 / 4 \mathrm{MS}+7 \%$ sukrosa & $2,6 a$ & Putih \\
\hline$-1 / 4 \mathrm{MS}+9 \%$ sukrosa & $3,1 \mathrm{ab}$ & Putih \\
\hline$-1 / 2 \mathrm{MS}+7 \%$ sukrosa & $4,0 \mathrm{bc}$ & Putih \\
\hline$-1 / 2 \mathrm{MS}+9 \%$ sukrosa & 4,2 bc & Putih \\
\hline - MS + 7 \% sukrosa & $4,5 \mathrm{c}$ & Putih \\
\hline - MS + $9 \%$ sukrosa & $4,8 \mathrm{c}$ & Putih \\
\hline
\end{tabular}

Keterangan: ${ }^{*}$ Angka-angka yang diikuti huruf yang sama pada kolom yang sama tidak ber beda nyata berdasarkan uji Beda Nyata Terkecil ( $\alpha=$ $5 \%)$. 


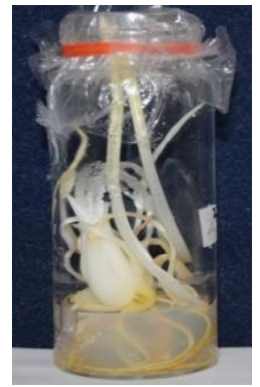

(a)

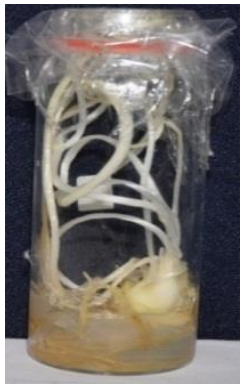

(b)

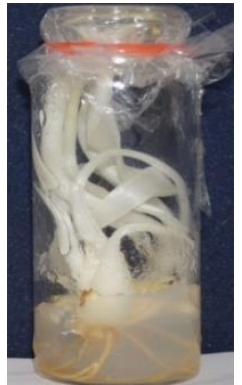

(c)

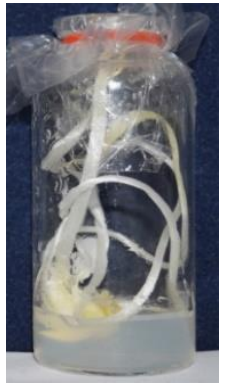

(d)

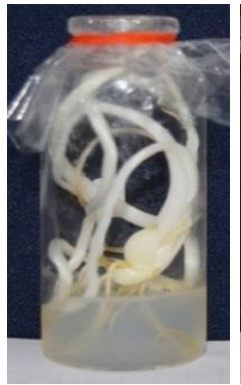

(e)

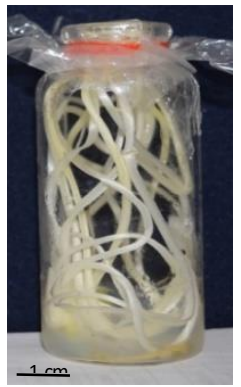

(f)

Gambar 2. Keragaan plantlet lili lokal L. longiflorum yang dikonservasi pada media $1 / 4,1 / 2$ dan MS (berturut-turut a, b, c) dan cv. Candilongi pada media yang sama (berturut-turut $d, e$, f) setelah 24 bulan penyimpanan.

\section{Keragaan tanaman in vivo pasca konservasi}

Plantlet diadaptasikan melalui penanaman secara in vivo untuk dievaluasi lebih lanjut. Hasil analisis sidik ragam menunjukkan bahwa tidak terdapat interaksi antara perlakuan media konservasi dan aksesi lili pada tinggi tanaman, jumlah bunga per tanaman dan lebar bunga mekar tanaman lili yang ditanam secara in vivo setelah penyimpanan 24 bulan secara in vitro. Tinggi tanaman, jumlah bunga per tanaman dan lebar bunga mekar tanaman lili yang berasal dari plantet yang dikonservasi pada berbagai media tidak menunjukkan variasi yang signifikan setelah penyimpanan secara in vitro selama 24 bulan. Perbedaan keragaan fenotipik tanaman lili pasca konservasi in vitro terlihat pada dua aksesi yang dicoba (Tabel 3).

Tinggi tanaman, jumlah bunga per tanaman dan lebar bunga mekar yang tidak bervariasi pada tanaman lili yang berasal dari plantlet yang dikonservasi secara in vitro selama 24 bulan pada media konservasi yang berbeda menunjukkan bahwa media konservasi yang digunakan tidak menyebabkan variasi pada karakter fenoti pik yang diamati. Hal ini mengindikasikan bahwa pengaruh perlambatan pertumbuhan aksesi lili akibat perlakuan konsentrasi media MS dan sukrosa yang tinggi pada media selama proses konservasi in vitro tidak berlanjut pada pertumbuhan tanaman saat ditanam pada skala in vivo. Hal ini diduga media MS dan sukrosa diduga tidak menginduksi variasi pada struktur genetik tanaman lili selama proses penyimpanan secara in vitro sehingga perlambatan pertumbuhan tanaman pada skala in vivo tidak terjadi. Keberhasilan konservasi in vitro melalui modifikasi konsentrasi media MS juga telah banyak dilaporkan pada beberapa tanaman seperti jahe (Syahid \& Bermawie, 2000), spesies liar anyelir (Catană et al., 2010) dan panili (Seswita \& Hadipoentyanti, 2003). Demikian juga penggunaan sukrosa pada konsentrasi tinggi sebagai osmo-regulator juga telah digunakan pada konservasi in vitro tanaman sagu (Sumaryono et al., 2012), kurma (ElDawayati et al., 2018), dan Capparis spinose (Al-Mahmood etal., 2012). 
Karakteristik bunga pada tanaman $L$. longflorum local dan cV. Candilongi hasil konservasi in vitro juga tidak berbeda dengan deskripsi awal sebelum konservasi in vitro dilakukan. Kondisi ini diduga disebabkan oleh konstruksi genetik kedua aksesi lili cukup stabil selama 24 bulan proses konservasi in vitro dengan perlakuan modifikasi media MS dan penambahan sukrosa. Hal tersebut juga sesuai dengan penelitian Bonnier \& van Tuyl
(1997) dengan menggunakan genotip yang berbeda. Sedangkan perbedaan tinggi tanaman, jumlah bunga per tanaman dan lebar bunga mekar di antara aksesi lili (Tabel 3) menunjukkan bahwa perbedaan konstruksi genetik berpengaruh pada potensi genotip dalam memanfaatkan kondisi lingkungan untuk pertumbuhan vegetatif dan bunga yang dihasilkan (Hassan et al., 2014).

Tabel 3. Tinggi tanaman, jumlah bunga per tanaman dan lebar bunga mekar pada pengujian in vivo yang berasal dari plantlet dua asesi lili dan perlakuan media konservasi in vitro se te lah 24 bulan penyimpanan.

\begin{tabular}{lccc}
\hline \multicolumn{1}{c}{ Perlakuan } & $\begin{array}{c}\text { Tinggi tanaman } \\
(\mathrm{cm})\end{array}$ & $\begin{array}{c}\text { Jumlah bunga } \\
\text { pertanaman }\end{array}$ & $\begin{array}{c}\text { Lebar bunga mekar } \\
(\mathrm{cm})\end{array}$ \\
\hline $\begin{array}{c}\text { Aksesi lili } \\
\text { L. longiflorum }\end{array}$ & $83,1 \mathrm{a}$ & $3,1 \mathrm{a}$ & $10,8 \mathrm{a}$ \\
cv. Candilongi & $66,3 \mathrm{~b}$ & $4,2 \mathrm{~b}$ & $12,1 \mathrm{~b}$ \\
& & & \\
Media konservasi & & & \\
1/4 MS + 7\% sukrosa & $72,1 \mathrm{a}$ & $3,7 \mathrm{a}$ & $11,3 \mathrm{a}$ \\
1/4 MS + 9\% sukrosa & $73,3 \mathrm{a}$ & $3,5 \mathrm{a}$ & $10,2 \mathrm{a}$ \\
$1 / 2 \mathrm{MS}+7 \%$ sukrosa & $74,7 \mathrm{a}$ & $3,6 \mathrm{a}$ & $10,8 \mathrm{a}$ \\
$1 / 2 \mathrm{MS}+9 \%$ sukrosa & $75,6 \mathrm{a}$ & $3,6 \mathrm{a}$ & $11,3 \mathrm{a}$ \\
MS + 7\% sukrosa & $75,6 \mathrm{a}$ & $3,5 \mathrm{a}$ & $11,0 \mathrm{a}$ \\
MS + 9\% sukrosa & $76,9 \mathrm{a}$ & $3,8 \mathrm{a}$ & $10,5 \mathrm{a}$ \\
\hline
\end{tabular}

Keterangan : Angka-angka yang diikuti huruf yang sama pada kolom yang sama tidak berbeda nyata berdasarkan uji Beda Nyata Terkecil ( $\alpha=5 \%$ ).

\section{SIMPULAN}

Konservasi in vitro lili melalui modifikasi konsentrasi media MS dan sukrosa pada dua aksesi lili dapat dilakukan selama 24 bulan dengan laju kematian dan pertumbuhan plantlet yang bervariasi. Laju kematian plantlet dengan pertumbuhan daun yang terendah diperlihatkan oleh plantlet lili yang dikonservasi pada media $1 / 4 \mathrm{MS}+7 \%$ sukrosa pada kisaran 27-31\%. Dua aksesi lili menunjukkan respon pertumbuhan yang berbeda selama konservasi in vitro dan evaluasi in vivo. Lili L. longiflorum menunjukkan jumlah daun yang lebih se dikit selama konservasi in vitro dengan performa tanaman yang lebih tinggi pada skala in vivo. Sedangkan cv. Candilongi memperlihatkan jumlah daun lebih banyak pada konservasi in vitro dengan jumlah bunga per tanaman dan ukuran bunga yang lebih tinggi. 


\section{UCAPAN TERIMA KASIH}

Penulis mengucapkan terima kasih kepada Badan Penelitian dan Pengembangan Pertanian, melalui Pusat Penelitian dan Pengembangan Hortikultura, Balai Penelitian Tanaman Hias yang telah mendanai kegiatan penelitian.

\section{DAFTAR PUSTAKA}

Al-Mahmood, H. J., Shatnawi, M. A., Shibli, R. A., Makhadmeh, I. M., Abubaker, S. H., \& Shadiadeh, A. N. (2012). Clonal propagation and medium-term conservation of Capparis spinosa: A medicinal plant. Journal of Medicinal Plants Research, 6(22), 3826-3836. https://doi.org/10.5897/JMPR11.547

Asker, H. M. (2012). Effect of bulb removal date on growth and flowering of Asiatic hybrid lily cv. Brunello. African Journal of Agricultural Research, 7(43), 57965799.

https://doi.org/10.5897/AJAR12.1331

Balangcod, T. D., Cuevas, V. C., Buot, I. E., \& Balangcod, A. K. D. (2011). Geographic distribution of Lilium philippinense baker (Liliaceae) in the Cordillera central range, Luzon island, Philippines. Taiwania , 56(3), 186-194.

Bonnier, F. J. M. (1997). Long term storage of clonal material of lily (Lilium L.). Wageningen University and Research.

Catană, R., Mitoi, E. M., Helepciuc, F., \& Holobiuc, I. (2010). In vitro conservation under slow growth conditions of two rare plant species from Caryophyllaceae family. Electronic Journal of Biology, 6(4), 86-91.

Cha-um, S., \& Kirdmanee, C. (2007). Minimal growth in vitro culture for preservation of plant species. Fruit, Vegetable and Cereal Science and Biotechnology, 1(1), 13-25.

Devi, M. P., Sahoo, M. R., Dasgupta, M., Prakash, N., \& Ngachan, S. V. (2015). Standardization of in vitro regeneration protocol for conservation of Shirui lily (Lilium mackliniae) - An endangered heritage flower under changing climatic conditions. Procedia Environmental Sciences, 29, 288. https://doi.org/10.1016/j.proenv.2015. 07.217

Dhyani, A., Nautiyal, B. P., \& Nautiyal, M. C. (2017). Distribution, status and conservation of Lilium polyphyllum (Liliaceae), a critically endangered medicinal plant from India. Plant Biosystems, 1-4. https://doi.org/10.1080/11263504.2017 .1330777

Dhyani, A., Sharma, G., Nautiyal, B. P., \& Nautiyal, M. C. (2014). Propagation and conservation of Lilium polyphyllum D. Don ex Royle. Journal of Applied Research on Medicinal and Aromatic Plants, 1(4), 144-147. https://doi.org/10.1016/j.jarmap.2014.1 0.001

Edirisinghe, E. S. C., Denagamage, C. H., \& Samarasinghe, W. L. G. (2017). Effect of nutrient medium composotions in in vitro conservation of Musa spp. Annals of Sri Lanka Departement of Agriculture, 19(2), 60-70.

El-Bahr, M. K., Abd EL-Hamid, A., Matter, M. A., Shaltout, A., Bekheet, S. A., \& ElAshry, A. A. (2016). In vitro conservation of embryogenic cultures of date palm using osmotic mediated growth agents. Journal of Genetic Engineering and Biotechnology, 14(2), 363-370. https://doi.org/10.1016/j.jgeb.2016.08. 
004

El-Dawayati, M. M., Baki, M. A. A., \& Abdelgalil, L. M. (2018). Effect of different conservation period with different sucrose concentrations on conserving somatic embryo clusters of date palm (Phoenix dactylifera L.) under minimal growth conditions. Applied Science Reports, 21(1), 14-21. https://doi.org/10.15192/PSCP.ASR.201 8.1421

El-Naggar, H., Osman, A., \& Sewedan, E. (2012). In vitro propagation and organogenesis of Lilium 'Prato.' African Journal of Biotechnology, 11(82), 14771-14776. https://doi.org/10.5897/AJB12.1512

Engelmann, F. (1991). In vitro conservation of tropical plant germoplasm. Euphytica, 57, 227-243.

Gao, Y. D., Harris, A., \& He, X. J. (2015). Morphological and ecological divergence of Lilium and Nomocharis within the Hengduan Mountains and Qinghai-Tibetan Plateau may result from habitat specialization and hybridization. BMC Evolutionary Biology, 15, 147. https://doi.org/10.1186/s12862-0150405-2

Hassan, N. A., Stino, R. G., Gomaa, A. H., \& AlMousa, R. N. (2014). In vitro mediumterm germplasm conservation and genetic stability of grape (Vitis vinifera L.). Journal of Horticultural Science \& Ornamental Plants, 6(1), 9-17. https://doi.org/10.5829/idosi.jhsop.201 4.6.1.1133

Huh, Y. S., Lee, J. K., Nam, S. Y., Hong, E. Y., Paek, K. Y., \& Son, S. W. (2016). Effects of altering medium strength and sucrose concentration on in vitro germination and seedling growth of
Cypripedium macranthos Sw. Journal of Plant Biotechnology, 43(1), 132-137. https://doi.org/10.5010/JPB.2016.43.1. 132

Ikinci, N., Oberprieler, C., \& Güner, A. (2006). On the origin of European lilies: Phylogenetic analysis of Lilium section Liriotypus (Liliaceae) using sequences of the nuclear ribosomal transcribed spacers. Willdenowia, 36(2), 647-656. https://doi.org/10.3372/wi.36.36201

Kaviani, B. (2011). Review article conservation of plant genetic resources by cryopreservation. Australian Journal of Crops Science, 5(6), 778-800.

Keatmetha, W., Suksa-Ard, P., Mekanawakul, M., \& Te-Chato, S. (2006). In vitro germplasm conservation of Garcinia mangostana L. and Lansium domesticum Corr. Walailak Journal of Science and Technology, 3(1), 33-50.

Langens-Gerrits, M. M., Miller, W. B. M., Croes, A. F., \& De Klerk, G.-J. (2003). Dormancy breaking in lily bulblets regenerated in vitro: Effects on growth after planting. Plant Growth Regulation, 40, 267-275. https://doi.org/10.1023/A:1025018728 178

Lucidos, J. G., Ryu, K. B., Younis, A., Kim, C. K., Hwang, Y. J., Son, B. G., \& Lim, K. B. (2013). Different day and night temperature responses in Lilium hansonii in relation to growth and flower development. Horticulture Environment and Biotechnology, 54(5), 405-411.

https://doi.org/10.1007/s13580-0131241-1

Marijana, S., Suzana, Ž., Jelena, S., Branislav, S. iler, Aneta, S., Sladjana, T., \& Dragoljub, G. ić. (2012). Efficient onestep tissue culture protocol for 
propagation of endemic plant, Lilium martagon var. cattaniae Vis. African Journal of Biotechnology, 11(8), 18621867.

https://doi.org/10.5897/AJB11.2076

Mir, J. I., Ahmed, N., Itoo, H., Sheikh, M. A., Rashid, R., \& Wani, S. H. (2012). In vitro propagation of Lilium (Lilium longiflorum). Indian Journal of AgriculturalSciences, 82(5), 455-458.

Mojtahedi, N., Koobaz, P., Fathi, M., Dabirashrafi, O., Azadi, P., \& Khosravi, S. (2014). Maturating, enlarging and breaking dormancy of in vitro lilium bulblets. International Journal of Horticultural Science and Technology, 1(2), 101-109.

Mojtahedi, N., Masuda, J., Hiramatsu, M., Hai, N. T. L., Mizunoe, Y., \& Okubo, H. (2013). Variation of dormancy and early flowering ability in Lilium longiflorum and $L$. formosanum populations in the Ryukyu Archipelago and Taiwan. Journal of the Japanese Society for Horticultural Science, 82(3), 234-241. https://doi.org/10.2503/jjshs1.82.234

Ozen, F., Aka, G., \& Aksoy, O. (2016). Genetic diversity and conservation strategies of some Lilium candidum L. population in Turkey. Bangladesh Journal of Botany, 45(1), 133-141. Retrieved from http://www.dnp.go.th/geneticsgroup/g enetic/paper/genetic diversity and conservation thailand.pdf

Pramanik, D., \& Rachmawati, F. (2010). Pengaruh jenis media kultur in vitro dan jenis eksplan terhadap morfogenesis Iili oriental. Jurnal Hortikultura , 20(2), 111119.

https://doi.org/10.21082/jhort.v20n2.2 010.p\%25p

Rahayu, E. S., \& Habibah, N. A. (2016). Optimization of in vitro conservation protocol of Carica pubescens Lenne \& K. Koch through medium concentration, temperature and irradiation duration decrease. Biosaintifika Journal of Biology \& Biology Education, 8(1), 85. https://doi.org/10.15294/biosaintifika.v $8 i 1.5371$

Rao, N. K. (2004). Plant genetic resources: Advancing conservation and use through biotechnology. African Journal of Biotechnology, 3(2), 136-145. https://doi.org/10.4314/ajb.v3i2.14931

Sanjaya, L. (2010). Perakitan varietas tanaman kerk lili yang berbunga tegak dan wangi serta tabung bunga pendek. Jurnal Hortikultura, 20(4), 321-331.

Seswita, D., \& Hadipoentyanti, E. (2003). Konservasi in vitro Panili (Vanilla planifolia Andrews.) melalui pertumbuhan minimal. Buletin Penelitian Tanaman Rempah Dan Obat, 14(1), 1-7. https://doi.org/10.21082/bullittro.v14n 1.2003.\%25p

Shawky, B., \& Aly, U. I. (2007). In vitro conservation of Globe Artichoke (Cynara scolymus L.) germplasm. International Journal of Agriculture \& Biology, 9(3), 404-407.

Skalova, I., Viehmannova, I., \& Vitamvas, J. (2012). In vitro conservation of Smallanthus sonchifolius under slowgrowth conditions. Agricultura Tropica Et Subtropica, 45(3), 147-150. https://doi.org/10.2478/v10295-0120024-5

Sumaryono, Muslihatin, W., \& Ratnadewi, D. (2012). Effect of carbohydrate source on growth and performance of in vitro sago palm (Metroxylon sagu Rottb.) plantlets. HAYATI Journal of Biosciences, 19(2), 88-92. https://doi.org/10.4308/hjb.19.2.88 
Syahid, S. F., \& Bermawie, N. (2000). Pengaruh pengenceran media dasar terhadap pertumbuhan kultur jahe dalam penyimpanan secara in vitro. Jurnal Penelitian Tanaman Industri, 5(4), 115-118.

Tahtamouni, R. W., Shibli, R. A., Al-Abdallat, A. M., Al-Qudah, T. S., Younis, L., AlBaba, H., \& Al-Ruwaiei, H. (2015). In vitro conservation and cryopreservation of plant genetic resources: A review. Jordan Journal of Agricultural Sciences, 11(1), 372-382.

Yung-Peng, D., Wen-Yuan, L., Ming-Fang, Z., Heng-Bin, H., \& Gui-Xia, J. (2012). The establishment of a slow-growth conservation system in vitro for two wild lily species. African Journal of Biotechnology, 11(8), 1981-1990. https://doi.org/10.5897/AJB11.2868

Zhang, M. F., \& Jia, G. X. (2014). The effects of sucrose concentration and light condition on lily's bulbet-in-tube production and inclusion content. Pakistan Journal of Botany, 46(1), 307315.

Zhang, Y. J., Xie, Z. K., Wang, Y. J., \& An, L. P. (2011). Changes in carbohydrate metabolism and bulb growth as induced by low-temperature release of dormancy in lily bulbs. The Philippine AgriculturalScientist, 94(2), 149-154. 